JANE MUNRO

Royal Central School of Speech and Drama

\title{
Crossing over: Choreographing audiences over borders - Forms and problematics
}

\section{Keywords \\ dance \\ borders \\ participation \\ audience \\ privilege \\ choreography}

\begin{abstract}
This article considers the potential of participatory artistic practice that debates borders through dance. It also asks why so many dance artists choose this form to debate borders, and what practices are typical of participatory dance investigations of borders. I discuss the range of border debates in works investigating dance and borders, and I begin to consider how privilege is dealt with by the work. I examine how dance works with participation and, alongside, look at the choreographic embodied invitation concerned. Particularly, I examine these questions through the dance work Rope Piece and consider how this dance practice as research generates a collective and participatory process in relation to borders and privilege.
\end{abstract}

Since the 2016 referendum in the United Kingdom and the vote for Brexit (the United Kingdom's departure from the European Union), there has been significant rise in dance and theatre works that consider national borders, the politics of territory and the role of bodies within that territory. 
A number of dance works that investigate the complexities of borders, all of them Intimate participatory pieces, have been commissioned by the Arts Council England, and UK based organizations Dance 4, and Dance Umbrella. The works engage a range of groups in participation, including between migrants and theatre audiences, concert dance audiences and derelict spaces, and pieces that explore borders with international audiences at the Migration Museum for example or groups of older and younger artists from international backgrounds. In the field of dance, there has also been significant study of site-specific dance and audience interaction by Hunter (2015) and Kloetzel $(2015,2019)$ in Choreographic Practices, for example. This takes into account debates concerning dance and borders. My analysis, however, focuses not specifically on site and how dancers respond to spaces, but examines how dance that is participatory, and asks the audience to join in the movement in the performance, might embody concepts of a range of borders. In addition this work might happen in the studio or be transposed onto any street.

Rope Piece (2016-18), ${ }^{1}$ follows Nelson's (2013) practice as research model by deploying theoretical research in combination with artistic context, followed by the subsequent analysis of making dance. Further, I draw on Midgelow's perspective that the choreographic research of creative thinking offers a'dance making, wherein making, beyond acts of more simply doing, encompasses reflective processes and products' (2019: 112). My practical dance research investigates how a dance artist's privilege might be addressed as part of a debate about borders through dance. Rope Piece was a research experiment and a dance work that considers the practical dance issues raised by a range of participatory dance works. This article will articulate those issues raised by participatory dance about borders and consider the practice as research that aims to address questions of privilege inherent in the practice. To this end I will offer a discussion of my practice Rope Piece, Charlotte Spencer's Is This a Waste Land? (2017), Rita Marcalo's Dances with Strangers (2016), Sivan Rubinstein's Active Maps (2018), and H2's Strangers and Others (2017). To contextualize my own and the work of these artists, I include a theoretical framework of feminist geopolitics which I apply not only to Rope Piece, but to this range of choreographic work that serves as a broader artistic context in which to locate my own work. Central to this argument will be the concept of 'crossing over', a framework offered by Anzaldua via Geiseking, which will allow me to consider how bodies hold territory as they move across borders, be they national or social, and how this can be considered in relation to dance. Arguments in the field of critical race are also highly relevant to researching dance and borders, such as the writing by Fernandez Rosa $(2015,2017,2020)$ writing particularly on race and dance in Brazil; alongside Brandstetter and Hartung (2017) writing on dance, borders and participation. Yet while they are beyond the scope of this current writing project they offer significant potential for future research. It is, however, the act of crossing over borders that functions for this intimate work in Rope Piece and the participatory game that evokes the crossing of borders. 


\section{Elements of the}

power relations

that are brought to the forefrout at

borders can also be

witnessed in the

theatre where the

audience member

is shown

their place, and

which space to

occupy.
Smith et al. (2016) argue that bodies are pivotal to the composition of territory and borders. They also state that bodies have a key function in the construction of territory and can undermine the authority of the state. As McKinnon (2016) notes, borders occur not just at national boundaries but can also be found even in the most personal areas of our lives, for example, an imagined border in a city which may mark out where people feel safe and unsafe. Dance is particularly pertinent to this issue because it foregrounds the body that is most often the site where borders are articulated. Dance is pertinent, therefore: an art form that can call forth and frame the embodied knowledge of territory. An embodiment that as a sense of the living body in its wholeness, as Hanna (1990) argues, a lived experience of territory can therefore called forth and framed in dance.

In participatory dance, the traditional theatrical proscenium border is dismantled and audience members are close up, touching and frequently participating and moving in the work, so becoming the performers. Here, in interactive practice, the understandings from experiencing the work are constructed in the embodied participation.

Elements of the power relations that are brought to the forefront at borders can also be witnessed in the theatre where the audience member is shown their place, and which space to occupy.

Certain trained people are allowed on stage, and others are not. In participatory dance, the spaces the audience occupy are broader and this enables constructed power relations to be confronted. Rope Piece uses participatory dance to reveal the social territories we embody. It combines text and choreography to create an experience of embodied territories for the audience and explore the manifestation of borders in daily life. We found that group situations occurred for us that revealed the silent borders of social and cultural positions, as well as those exposing national borders. These might be described as social or cultural borders, as Kurki (2014) articulates in the article Borders from A Cultural Point of View. He argues that conceptions of borders have developed from the understanding 'of the border from a territorially placed boundary and filter, to a semantically constructed, ritualized and performed symbolic border' (2014: 1055). We aimed to create a participatory dance practice that revealed the situations of our own social borders that might have become ritualized and symbolic. Through an embodied dance game, we wanted to acknowledge both privilege and lack of privilege, and we looked at similarities and differences first between each other and then with our audience members. We asked questions concerned with borders of class, gender and ethnicity such as:

Are you a parent?

Do you get your coffee in the artisan café or the workers' caff?

How single are you feeling today?

Are you from the East or the West? 
Our audiences asked questions such as:'are you gay or straight?','has your country been responsible for major wars?' and 'have you ever felt really lost?' These questions offered issues that transcended simple binaries. This was a game with a rope in which we and our audience acknowledged territories we identified with or felt other to, and it develops from the drama game of 'anyone who' which drama facilitator Swale (2015) describes. This theatre game seems to echo and highlight Kurki's concept of the construction of borders as social and performed, and participatory dance seems a suitable place to remind people of this in its ritual structure through dance. In addition, we aimed to address the delicate power relations within participatory art works and within border debates through dance. Specifically, it is the power a professional performer negotiates in participatory work. We also aimed to acknowledge our positions as privileged western artists, albeit one from the Global North and one from the Global South, positionalities that were vital to acknowledge and investigate when working with participants in dances about borders. Often in our practice, participants were from the Global North but sometimes, like Bogue, my collaborator from the Global South.

Taking the structure of a game, Rope Piece (2016-18) begins by asking audience first to unravel a skein rope, before moving more pointedly towards direct questioning of participants. As performers, we cross from one side of the rope to the other in response to the questions, before asking the audience to join us in this temporary border crossing, requiring us all to identify with a space, place or socially bordered territory. Through the use of direct address, speaking directly from our subject position and not from the perspective of a 'character', we aimed to offer no representation other than the rope as border. As the game structure developed, we began physicalizing questions of sameness and alterity, opening up the potential for discussions of privilege, which is acknowledged and navigated in dialogue with other bodies in real time, rather than through a proscenium based, disembodied empathetic response. It is useful to consider Rope Piece in relation to Anzaldua's argument that bodies form territories through their everyday actions. The piece thus opened a haptic interrogation of theoretical debates concerning borders.

Diener and Hagen (2012) state that borders are political, social and cultural boundaries, and in the field of border studies Smith et al. (2016) discuss the considerable interest in how the body is implicated in boundary-making practices. Feminist geography has offered a critique of traditional areas of geopolitical study, and shifted focus to those areas at the edge of society, and particularly on spaces and territory of the small and the local spaces of daily life. Rope Piece is in direct dialogue with these ideas and is part of a growing body of work that uses bodies as a means to interrogate considering the policing of territories and the politics of border-crossing. Significantly, these practices embody critical perspectives like those offered by Smith, Swanson and Gokariksel and suggest how bodies might disrupt borders and embody challenges to state borders. 


\section{Dances, borders and participation: Four participatory dance works and Rope Piece}

- Is This a Waste Land? (2017)

- Dances with Strangers (2016)

- Active Maps (2018)

- Strangers and Others (2017)

Such examinations of territory are pertinent to dances that choreograph borders for audience members' bodies, and the consideration of borders and territory is highly relevant to the community dance practices that encourage bodies to consider the crossing of neighbourhood borders. To consider this further, I turn here to feminist geopolitics, specifically the writing of Geiseking (2016), who, drawing on Anzaldua, argues that borders can limit our understandings and opinions, and that crossing them can enhance our viewpoints. She develops the understanding of territories and borders in terms of what bodies' daily crossing from neighbourhood to neighbourhood might do. Using Anzaldua's (1987) concept of 'crossing over', she considers the role of the body walking across a social border, which is significant here rather than the actual border. She considers not the national border, but the boundary between neighbourhoods, and particularly what might be called 'gaybourhoods', specifically describing the movement back and forth of women to Greenwich Village. What this crossing does, Geiseking argues, is reveal that social territories are constructed by minority groups, in this case urban lesbians, not by their ability to buy property but by their ability to create safe communities in which they walk, eat, dance and freely show public affection. Geiseking explains that we can develop diversity by transgressing boundaries that constrain our identity and the spaces related to them. So by entering spaces and social situations that are not 'our' perceived place, the meanings attributed to bodies and spaces can be shifted and respect amid diversity can be enhanced. Everyday actions of crossing a road, walking down a street that we usually do not or buying a coffee in a different café can shape a territory with actions of the body. By taking our bodies to new places, can give a different territory to that space.

These emerging dialogues of disruption echo the work of Portuguese/British choreographer Rita Marcalo. In the piece Dancing with Strangers: From Calais to England, Marcalo and her company Instant Dissidence investigated the dance movement of inhabitants of the migrant/refugee camp, known as the Calais Jungle at the French/English border. Movement and dance were taught by a small number of migrants and learned by Marcalo and brought across the border by her to be performed in England. The one-to-one participatory dance piece was performed in festival contexts, but I will focus on the iteration offered as part of the Hazard Festival, Manchester (9 July 2016). In this version, Marcalo performed a dance taught to her by Yodite Melku, an inhabitant of the Calais refugee camp in 2016, who talked with Marcalo about her experiences as a migrant and shared a short dance concerned with her desire to travel to England. In this initial exchange, the porous 
borders of one body encountered another, and Marcalo's subsequent performance of the material at Hazard, became part of a larger haptic migration. When Marcalo, wearing a t-shirt emblazoned with the words 'Dance with $\mathrm{Me}^{\prime}$, approached people in the street, arms wide open, she was looking for ways to cross the borders of normative audience/performer dynamic, while bringing Melku with her. Participants are then shown Melku's movement in a one-to-one dance exchange, learning through mirroring and repetition.

The experience and understandings gained through these crossing-over acts might be explained through theories of embodied cognition (EC). The theory of enactivism and the embodied mind develop from phenomenology and the writing of Merleau-Ponty, as Gallagher (2017) notes. It reviews the position of the extended mind, acknowledging the positions within EC, particularly drawing on Varela et al. (1991). ${ }^{2}$ Gallagher (2017) argues that the body plays a forming role in understanding, and this body is informed by its situation in the world. He states that simple understanding and people's interrelations are inseparably connected with their bodies, the movement and actions they perform and the circumstances in which they find themselves. If understanding can be in action, as well as through the critical reflection afforded through watching, investigating the lived experience of crossing borders into new territory through participatory dance can provide understanding through the body. If new respect amid diversity can be enhanced through crossing over, I suggest that this respect can be generated through embodied understanding of other's territory and everyday actions within that boundary.

For the participant, there is the potential to experience what Gallagher (2005) understands as an adjustment of the body schema, through an altered experience of bodily awareness as the participant learns the different shapes made by Melku with which they become accustomed. By witnessing Marcalo, learning the dance and listening to Melku tell her story through headphones, the work facilitates an embodied engagement for the participant to experience a physical empathy with the migrants in Calais while on the streets of England. Through repeating the Melku's dancing while copying Marcalo, the audience member develops a felt familiarity with the action, acquiring a heighted experience of the body by attending to it, or an embodied knowledge, of the simple action. This one-to-one performance exchange facilitates an attention both to the body of the audience member and to Marcalo's body awareness, and so to a physical understanding of Melku's position of refusal at a national border.

The process of enacting her physical score while listening to her share her experiences opens up and potentially unsettles the usually distinct audience/performer binary, and encourages a moment of border crossing.
The process of

enacting her

physical score

while listening to

her share her

experiences opens

up and potentially

unsettles the

usually distinct

audiencel

performer binary,

and encourages a

moment of border

crossing. 
At a time when borders are hardening, this transgression of the movement that has been shared in a Manchester square with participants, offers an important and subversive act that facilitates respect for diversity and mutual embodied understanding.

Much like in From Calais to England, Charlotte Spencer's Is This a Waste Land? (2017) uses headphones to merge choreography with participation in an exploration of borders. In contrast to Marcalo's one-to-one dynamic, Spencer's piece expanded the audience to approximately 40 people and was located in a disused dockland space between an historic flour mill and London City Airport. Here the work asked the audience to interrogate questions of dereliction and, following instructions spoken on headphones, were encouraged to cross into an abandoned space. As the piece developed, so too did the engagement of the participants. Is This a Wasteland? offered direct and explicit instructions to the audience via headphones, and through these exchanges generated clear choreography for them. As an audience member I noticed distinct rhythms emerge in the structure of the work; there were moments in which I was isolated from the other audience members as my headphones fell silent, while at other moments as I moved with other participants, collecting found object and moving poles. I found a sense of the collective emerge through these shared tasks, only to have this replaced by the more intimate connection with the voice in my ear.

As in Geiseking's geographic discussion of neighbourhoods, Is This a Waste Land? highlights the potential for diversity that arises in the transgressing of spatial boundaries that describe our identity. The embodied experience of working together, as we are asked to scavenge and examine (maybe recently) discarded objects such as shoes or cups, highlights that this is a space in which some people - not us - live. Here, a respect for those without home or place was enhanced, as Geiseking (2016) and Anzuldua argue by crossing over into this other territory, and we can enhance our understanding of difference. In Is This a Waste Land? the dance theatregoer was invited to cross over into the illicit space and to engage in the practices of living in his no man's land territory, but also reminded us of that perhaps we were collaborating with the 'owners' of the space we occupied; not in the sense of those who had abandoned the space, but through an engagement with those who had repurposed this space, turning it into home. Inevitably, questions of privilege begin to emerge through this interaction, as the dusk brings a reminder to those of us privileged to return to a warm home on a cold autumn evening.

Echoing both Dances with Strangers (2016) and Is This a Waste Land? (2017), it was our aim for Rope Piece to enter into an explicit dialogue with a haptic engagement with border crossing, and the (hopefully) attendant shift in empathetic response. Geiseking (2016) applies Anzaldua's argument to bodies and spatial boundaries in her geographic research in New York City to highlight how these social borders both define and remake our difference in terms of the spaces we visit, and with whom we visit them and particularly, what we do in that space. As Geiseking argues 'crossing over changes the imagined perception of spaces, in that social borders can be crossed in the everyday production 


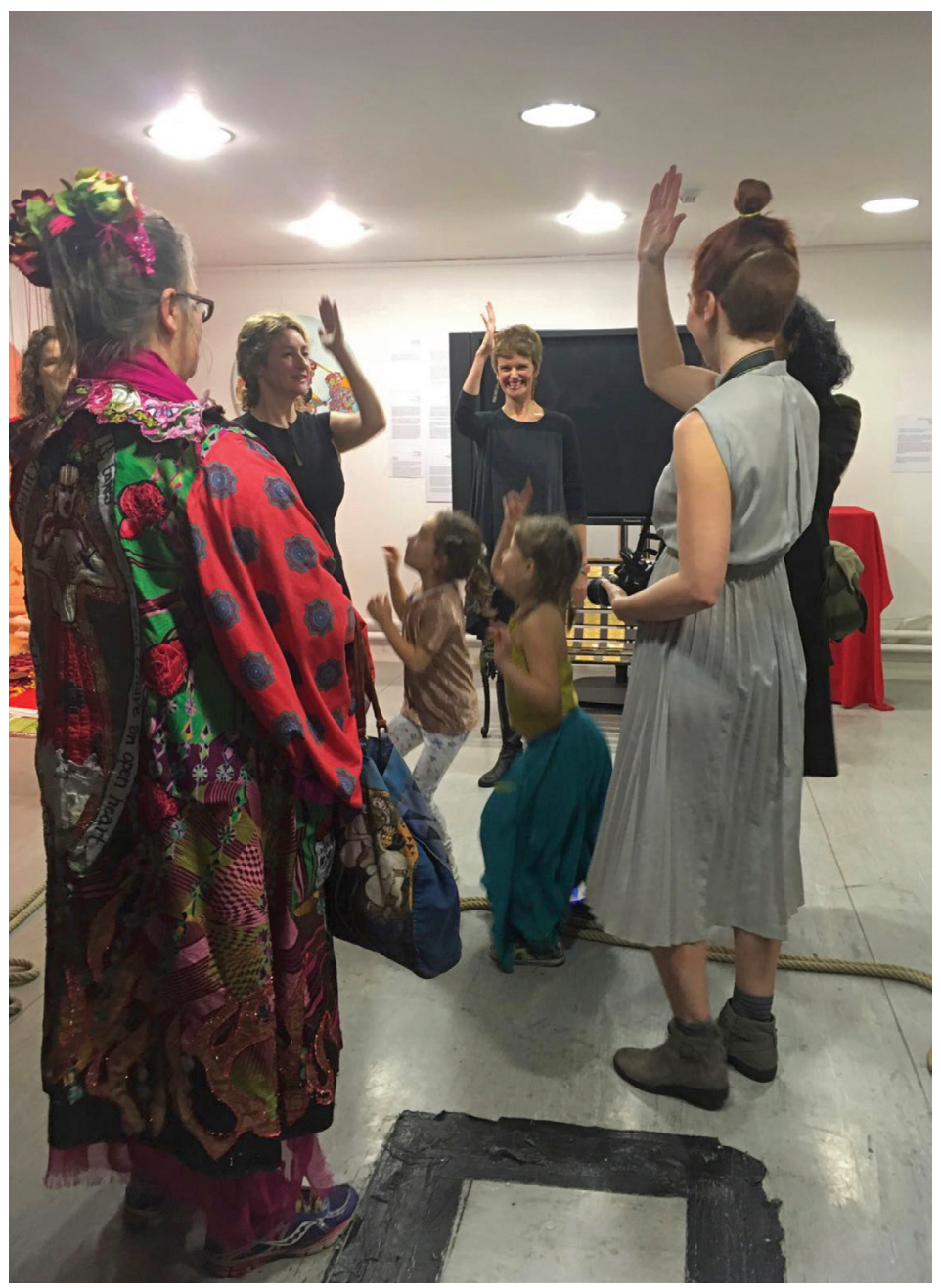

Figure 1: Photo: Nohar Lazarovich at FiliArt: London (2016). 


\section{As the dance game \\ began to reveal \\ our own identities \\ and relationships \\ to borders, it

also opened up
questions of
visibility, privilege
and difference.

of territory through bodily actions' (2016: 263). In Rope Piece, distinctive questions relate to various kinds of borders, highlighting that silent or social borders and difference in territory are apparent within and at the same time as the nation state borders.

The complexity of national and social borders is called forth in these questions held in the bodies of the performers, and which is developed by playing this game of audience participation. My collaborator Bogue did not grow up in Britain like me, but in Brazil, in the Global South.

As the dance game began to reveal our own identities and relationships to borders, it also opened up questions of visibility, privilege and difference.

The question 'are you from the North or the South?' expanded beyond questions of nationhood, to wider questions of the global-local. Bogue's capacity to speak Portuguese, and her connection to the wider Lusosphere, makes connections to bi-lingual and diasporic members of the audience differently possible. These questions of linguistics allowed further conversations around inclusion to emerge, when one audience member offered that her other language was Sign Language. As gestures from this linguistic structure were shared through performance, the potential crossing of another, often invisible border, was considered.

\section{Question: 'How do you say north and south?'}

For Rope Piece an embodied understanding of borders debates through participation is key. Yet participation concerned with bodies and borders can potentially enhance understandings of diversity but can also be provocative. Therefore, the piece was developed in recognition that participation requires detailed consideration and exploration of the conjoined concerns of power and privilege, to ensure that the audience is kept emotionally safe. By drawing on both the embodied knowledge of the dancer and choreographic knowledge of power relations and audience participation, we brought the audience's attention to their own bodies. By walking in between them, by sitting next to them and brushing their shoulders as they formed a group on entering the space, we aimed to remind the audience of how they sense their bodies, rather than what it is to watch bodies. As performers, we took time to sit next to or lie beside someone, close enough to sense one another's arm or leg through clothing, and we also facilitated this in an embodied collective by asking the audience to interact in order to unravel the rope together. The figure below shows the closeness the performer (in jeans) is lying next to the audience member (in green t-shirt). ${ }^{3}$

This sense of direct, active engagement between audience and performer can be seen in Rubinstein and MacPherson's piece Active Maps (2018). The audience, having walked over a world map taped on the floor created by MacPherson, were encouraged to begin making their own map with masking tape. Like Spencer, Rubinstein and Macpherson use material and marking as a means 
to engage the audience and encourage active participation. Rubinstein and MacPherson's participatory exploration of national borders, spatial mapping and movement dynamics provided the beginning of a sensuous understanding of national borders and a consideration of home. According to immersive theatre writer Alston (2016), sensuous understandings facilitate an exchange for the audience member in immersive theatre'whereby sensuous experience produces its own kind of knowing that may or may not be graspable by means of conscious rational reflection' (2016: 219). Rubinstein's spoken invitation to the audience to be flexible or direct with their walking across their maps facilitated an embodied consideration, or sensual understanding of these maps and national borders. With this adjustment from soft to hard lines in the body, Rubinstein began to generate a sensuous knowledge interweaved of hard and soft space in relation to maps and considering borders.

It is through this sensitized, embodied participation that the experience of crossing over can offer new insights. In Rope Piece, the invitation to listen to the body allows for a stilling and an ability to witness one's own subjective position in relation to those others sharing the space. From here it becomes more possible to understand and interrogate the social borders at play for ourselves and others. For example when the question was asked in the game 'who is single and who is not', someone might stand astride the triangular rope to identify an ambivalence about marital status, so occupying both married and single spaces. At this moment it is important to allow time, stillness and space for these borders to be acknowledged as we acknowledge the ambivalence to the binary of married or single, for example and also noticing who sits, stands or lies in the same spaces marked by the rope. As Gallagher (2005) argues, the body and mind adjust proprioceptively to one's environment, and in a continuing manner. Moving to sit with or stand in particular configurations in relation to these questions of borders marks a bodily response to particular questions of social borders. Alongside, it points out our relation to other bodies and those social borders. It also reveals that place, be it country or city, affects our border and social status. Rope Piece aims to allow time and space to be close to other bodies and reverent to our bodies that hold these sometimes-changing and static social borders, and aims to do so with respect of multiple positions.

\section{Question: ‘Are you a parent?’}

Strangers and Others (2018) choreographed by H2 Dance is not only concerned with national borders but also social borders and those of identity politics. Much like Rope Piece, it is a dance game of questions, which I experienced at the Albany Theatre, London, as part of the Fest en Fest festival. Interacting in the space with the company, the audience were asked to move through the bare theatre space in response to specific questions. Our bodies and the space were the only materials at play. I found the strategies employed by the company and the line of the questions particularly revealing. For example, at one point we were asked to stand in a line according to who earned the most money, 


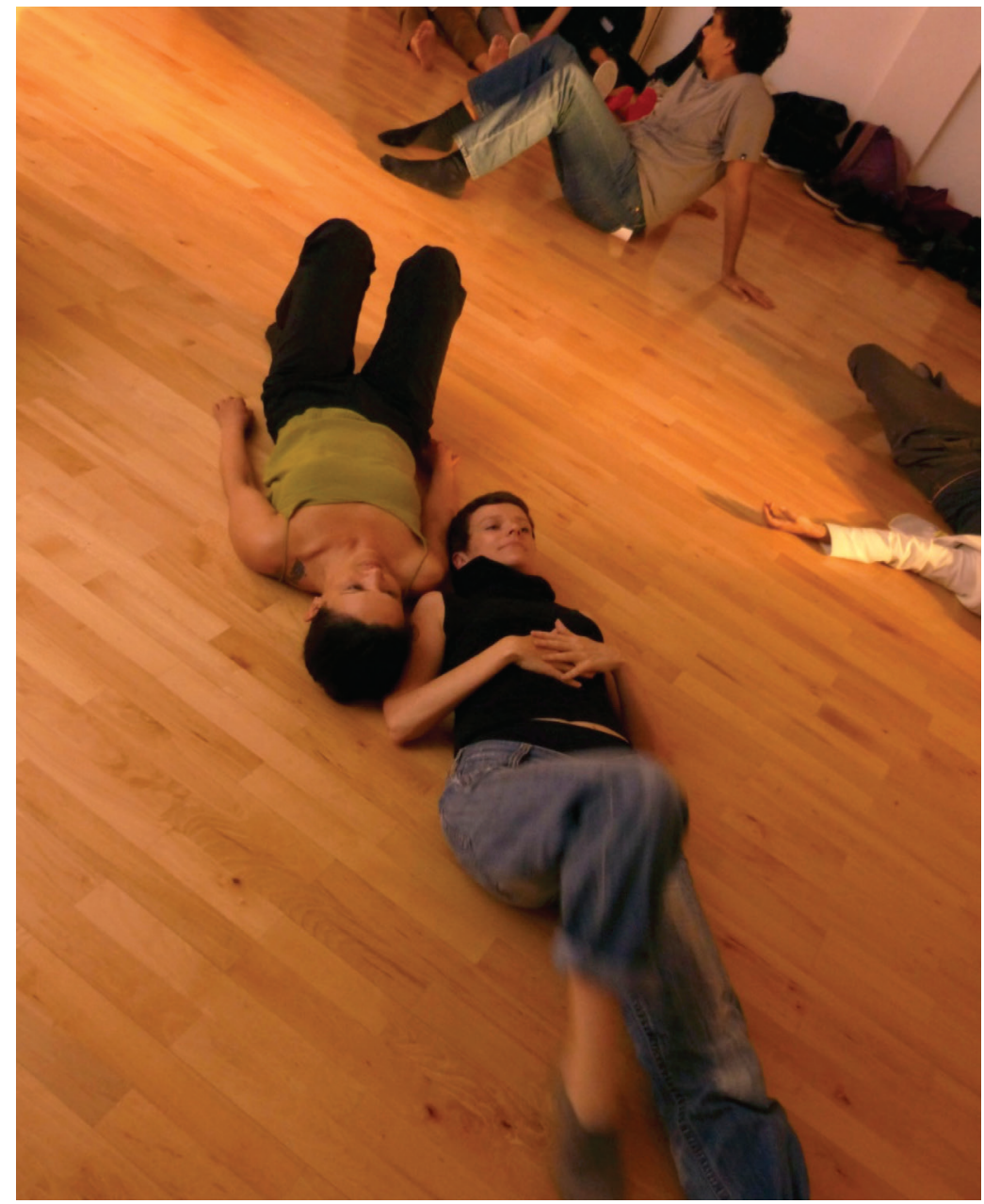

Figure 2: Photo: Saolo Silveira, Dialogues on Dance Conference, Coventry (2017). 


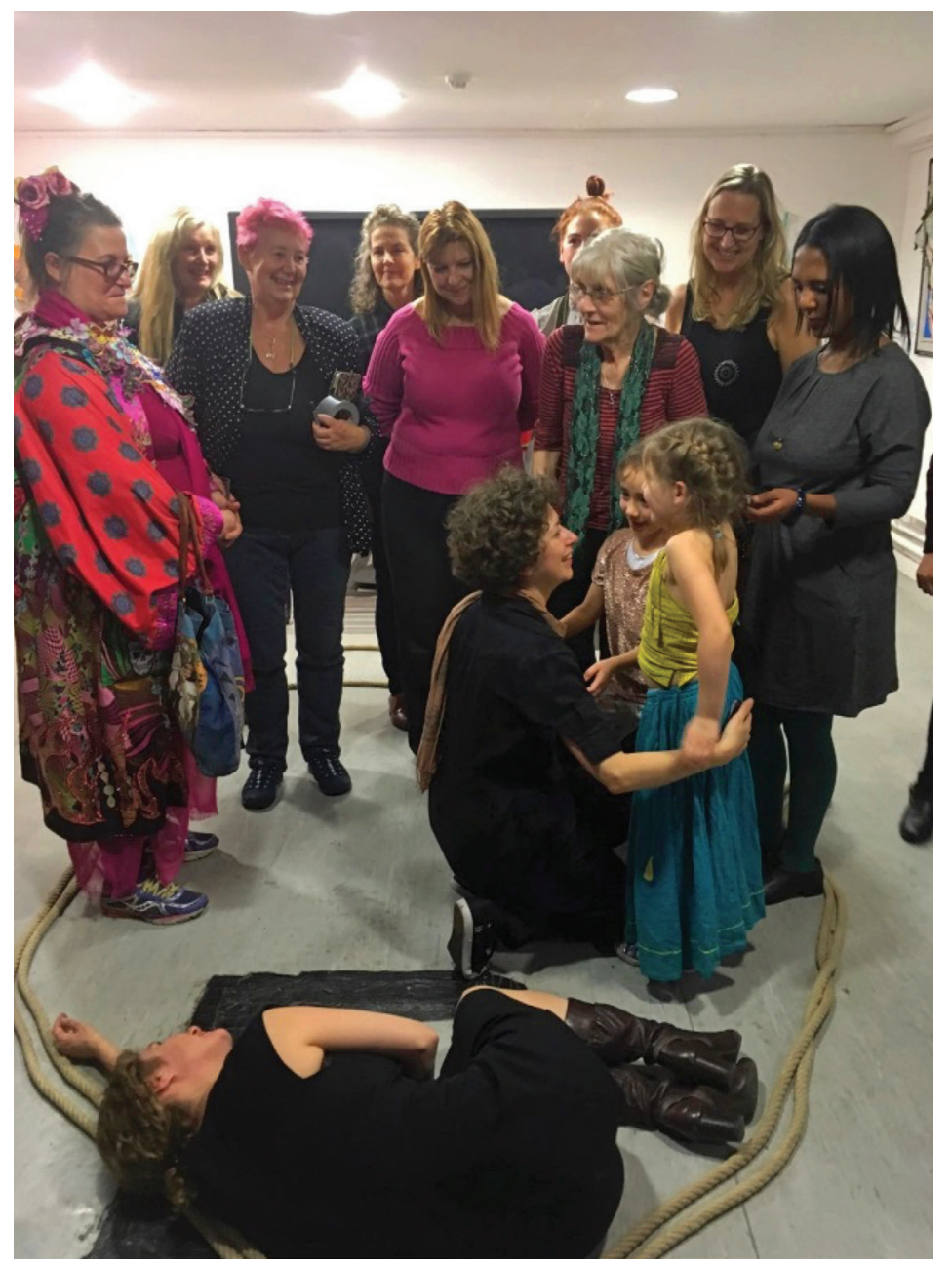

Figure 3: Photo: Nohar Lazarovich at FiliArt: London (2016). 
and it was impossible not to reflect upon the clear gendered dynamic at play in the space, with a man in his 40s standing at one end of the line, and a young woman standing at the other. There were also questions regarding touch and nationality, and the range of questions addressed my interest in how social borders affect people in a range of spaces within daily life from the border of their skin to their socio-economic status, or their nationality or their relation to hard nation state borders.

The audience was invited to play this game through interaction with performance text delivered through headphones. The choreographers spoke their instructions, live and unseen, from somewhere in the auditorium. The audience were instructed to move in space in relationship to other audience members, and to touch other audience members, with instructions designed to encourage the audience member to pay attention to themselves, to others in the space, to the space itself, and in turn an embodied engagement with social border debates being explored. Despite the occasionally confronting nature of the questions, the choreography of bodies in space was clear and the instructions were well defined. That being said, the absence of a bodily present performer might have impacted on the potential for connection to the work as it was impossible to know what social position $\mathrm{H} 2$ occupied, or what borders they were crossing themselves.

To summarize, in each of the above works borders are considered differently: sometimes considered in relation to a nation state, or to silent borders within a city or to social borders. In each of the choreographic works, there is a play with bodies crossing over borders, or not, showing the significance of bodies in the creation of borders and territory. Spencer's dance work focused on what Fortuna (2017) describes as silent borders in relation to crossing over into illicit spaces, while Marcalo's and Rubinstein's works concentrate on how we might embody performances of national state borders in participatory dance. H2's work brings together a range of different questions of both social and national hard borders. Each of the dances, however, works with the audience engaging in the sensuous practice of dance in relation to these borders. In addition, this engagement is facilitated through working with scenographic materials in the cases of Is This a Wasteland? and Active Maps. Alongside, the works also navigate the use of text, audience instruction and headphones differently. H2, Marcalo and Spencer all use headphones, while Rubinstein uses live performer speech. H2 and Spencer are not visibly present in the work, yet in the case of $\mathrm{H} 2$ the voices are those of the choreographers who are watching and talking live to the audience from auditorium. By contrast, what is significant in Marcalo's work is the voice is of Melku, the migrant young woman speaking in Calais. By using the voice and movement of the dancer in the community, Marcalo's piece extends participatory concert dance with its use of the movement, text and voice of Melku, rather than that written or performed by a trained artist.

To return to Geiseking's feminist geopolitical practice of inviting participants to draw imaginary or mental maps of New York City, it is the bodies entering and exiting spaces identified with specific identity that defines their personal territory. In Rubinstein's participatory choreography, this practice 
of mental mapping was used as a strategy for the audience to map out their two homes with masking tape, with the audience crossing back and forth. The dance invited an embodied understanding and tolerance of moving between two spaces, yet also revealing the privilege available in the freedom to cross over, at this point in history when free movement of people for some, is possible but is under threat. Rubinstein and MacPherson began to generate a practice that uses the material of masking tape to generate participation, and taught movement dynamics to generate an embodied audience choreography that while dealing with freedom of movement, also highlighted the privilege that is afforded some. Each of the works presented offers an implicit statement in relation to how privilege is considered. Yet together these works suggest the possibility that borders and privilege are evident within these nation state borders, in social borders.

This returns me to a consideration of my own embodied explorations in Rope Piece. Given the period during which the work was being developed (2016-18) questions of national borders were informed by the ongoing debate about Brexit. The questions of 'are you a Londoner?' asks the audience to step inside a large circle, while the question 'are you British?' provocatively asks the audience to sit inside or outside a rope constructed map of Britain. Self-identification might allow participants to feel comfortable positioning themselves as a 'Londoner' (speaking as it does to residence and the adoption of a place of residence as 'home') while struggling with the concept of 'Britishness' in the light of uncertainty. These questions have the potential to perform the harsh nature of national of borders, and as a result needed to be dealt with a level of delicacy to ensure all participants felt able to participate. The live manner in which this was asked was crucial, and the order of the questions also acknowledged our own difference. Questions of belonging were asked after the revelation of Bogue's other Brazilian home. We asked the question'is there another place you call home?', because she acknowledged this border position herself, and one with which the audience might identify with also. It also comes towards the end of the piece that the audience members follow our lead in mapping out their other home, using the rope to describe its location on the floor, their attempts forming looping circles, triangles or uneven attempts to sculpt the actual shape of their town or country. This section became a celebration of other places with audience members calling out different towns identifying with their places. People actually call out the names of their other home: I heard 'Madrid' called out by one woman, and Bogue called out 'Sao Paolo' in one iteration. Here a tension emerges; the piece reveals the potential of privilege, of being wealthy enough to have two homes, while in the same moment acknowledging those people speaking of a home elsewhere may well be speaking of being displaced. It is, however, an engagement with the material of the rope that generates a sense of community or isolation, and an embodied consideration of a range of different borders. By actually creating the represented border and by playing with the rope in the same space as others, creates an ease of entering and exiting of travelling with others and alone. The rope particularly marks the spatial pathway of this line and frames the steps of the audience members. 


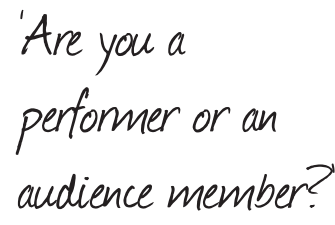

The crossing-over in Rope Piece is a represented form but aims to provide a communal experience and a witnessing of how individuals are the same or different to others.

Unlike the dances of Marcalo, Spencer and H2, Rope Piece does not use headphones; instead the game asks for repetition as an essential choreographic tool in that the audience needed to see the game happening, and initially at a distance. This strategy is twofold: firstly, the performance of the questions shows the audience what the game is, and secondly, the repetition is a choreographic tool in which the revelations and action of the performers are developed by adding bodies, those of the audience, to the initial score. As choreographer Meg Stuart describes:

To see an image and then to re-see it, to experience it more than once, to go beyond the first impression so that it becomes something completely else to you than when it first flashed by.

(Stuart in Burrows 2010: 8)

The repetition, of course, contains a participatory offer: an implied invitation to join the score is added to the choreography. In order to generate the participation the series of questions are repeated starting with the opening question:

'Are you a performer or an audience member?'

This was a useful invitation with an enthusiastic audience at a social event, such as at the Library Theatre in Covent Garden, when the audience needed little prompting to join in. At more serious showings, such as at the Dialogues on Dance Conference, Coventry (2017), it was an implicit offer that was avoidable, and the invitation needed to be more connected to their introverted situation, particularly as this audience were not in a playful space but a reflective environment. In this example the use of headphones may have suited their context.

The dance research generated challenges in terms of creating immersive provocations, and therefore, it was vital to make a very clear participatory offer in the environment of either a gallery space or a theatre. We tried working with no performers in one gallery setting, merely asking the questions to the audience after facilitating their unravelling ropes but without headphones; however, this was uncontrolled without sufficient space to see the choreography or the movement answers to the questions. Therefore, the repetition was vital for this work of embodied labour without headphones. In relation to participation revealing border debates, it was necessary to see who was crossing over into which territory to reveal their changing allegiance, and therefore headphones might have facilitated this witnessing further. To facilitate clarity, the piece included the presence of performers who enabled this, in contrast to H2's performers who were only present through voice in headphones. For Rope Piece, with its live performer address rather than headphones, the privilege of the dancer/ choreographer and that of the work was clearly located. 


\section{Conclusion}

The review of contemporary participatory dance reveals five significant issues relating to borders: firstly how borders are considered, secondly how the work acknowledges its privilege, thirdly how text, voice and headphones might be used in relation to power, fourthly facilitation of embodied dance for the audience and lastly how materials are used. Rope Piece contributed to these practices by offering a dance experience of a range of border issues whilst also foregrounding the privilege and identity positions of the performers. Rope Piece functions as a critique of participatory border choreography, probing the strengths of existing work.

Firstly, in terms of the consideration of borders, Rope Piece focuses on the roles of the body in defining territory in this game of questions and shifting patterns of movement. The questions drew attention to geographical and real borders as well as those that are social and metaphorical. In this it is similar to H2's Strangers and Others, which asks its audience to think about and notice their position in terms of borders, particularly social borders and identity. It, however, contrasts to both Rubinstein's work and that of Marcalo which, while they clearly investigated hard national borders, did not link them to social borders. The common trope of all of the pieces discussed lies in that they all draw attention to borders while undermining the border of the theatrical proscenium. Specifically in Rope Piece, by foregrounding the participation, and including the question 'Are you are performer or an audience member?' allowed for the borders present in theatre to be questioned. It also raised questions of how to work with the power the artists and the performers hold. In a way that is different to the other works, Rope Piece acknowledges the possible confusion generated by audience participation and offers a comparison to the chaos that crossing borders can generate. This can be seen as the dance game becomes more chaotic, and the question 'Have you ever felt really lost?' offered an acknowledgement of the deterioration of the form of the game. Alongside, through removing the border between dancer and audience member, it becomes easier to consider social borders because the audience and performer occupy the same space. A set of possibilities and problems that are grappled with differently by $\mathrm{H} 2$.

Secondly, Rope Piece attends to how privilege is acknowledged in this work about borders. The questions in Rope Piece are autobiographical and offer a revelation to the audience of our Brazilian and British identity positions in order to make the audience feel safe in exposing their own. The piece acknowledges difference, and also how we the performers are both privileged and under-privileged in terms of the Global North. Examples of these differences include: marriage, parenthood, socio-economic status, and culture; questions we asked ourselves before asking the same questions to the audience. It seems suitable in a work about borders, and therefore power and privilege, that an acknowledgement of the choreographer/performers position might attempt a levelling of power with audience members. 
Thirdly, Rope Piece uses live speaking to the audience in a shared space in order to pose confronting questions. By placing the performer's speaking and dancing body in the work, rather than a disembodied voice that instructs, aimed to be egalitarian between performer and audience. Each of the pieces discussed used different methods in terms of text, voice and headphones performing different use of the voice and power. For Rope Piece, similar to Rubinstein's Active Maps, direct and live address was important in considering borders, and generating care seemed more possible for us when the dancers shared the space and played the game. In contrast, H2 and Spencer spoke using headphones that enabled impressively clear choreography as well as intimacy through text spoken into the ear.

Fourthly, in terms of facilitating embodied dance for the audience, it is evident that a delicate participatory dance practice requires significant detail in how it invites them. Rope Piece began by sensitizing the audience to close-up practice sharing with the audience members, the dancers' group work process. It is of course not only the questions that reveal the identity positions, but also the bodies of participants and performers alike. This initiation of the audience into the embodied practice of the dancer shares similarities with the other pieces discussed. Each piece offered a delicate invitation to participate in embodied dance and a crossing over onto the stage to perform, so emphasizing the significance of embodiment in relation to border debates.

Finally, the trope of using materials in dance that is both participatory and about borders can be seen in three of the works. Our use of rope and the use of masking tape to create maps in Actice Maps clearly mark out borders and allow for a physical play of doing borders. In Is This a Wasteland? an embodied engagement with the materials found in this illicit space deepened the understanding of the space and allowed for a complex crossing over to momentarily inhabit this abandoned place. The use of rope which also happens in Is This a Wasteland? is specifically emphasized in Rope Piece and offers the communal aspect in that one feels the pull of another through the body's engagement with rope. One not only witnesses the representation of borders but also senses a pulling through space when one person takes more control than another.

Participatory concert dance that debates borders therefore offers a critique to the proscenium concert dance that considers borders, because it foregrounds the social boundaries within it. In addition it critiques the valuable community dance that Fortuna describes, which does not facilitate the workshop participants performing on the professional stage. Participatory border concert dance invites the audience members into the show alongside performing the applied practice as professional dance. By doing so it facilitates two pertinent social border crossings. The dance game of Rope Piece is indicative of the potential of this participatory border concert dance. It reveals the multiple layers of borders that are apparent in social territories. As part of this process Rope Piece (by creating a collective through embodied, danced labour with community participants, and specifically with the dancers performing live) aims to acknowledge privilege and power relations and aims to address the difficulties of creating such dance works. 


\section{References}

Alston, A. (2016), Beyond Immersive Theatre, London: Palgrave Macmillan.

Anzaldua, G. (1987), Borderlands/la frontera: The New Mestiza, San Francisco, CA: Aunt Lute Books.

Berlucchi, G. and Aglioti, S. M. (2010), 'The body in the brain revisited', Experimental Brain Research, 200:25, n.pag.

Brandstetter, G. and Hartung, H. (2017), Moving (across) Borders: Performing Translation, Intervention, Participation (trans. Interweaving Performing Cultures), New York: Columbia University Press.

Burrows, J. (2010), A Choreographer's Handbook, Oxon and New York: Routledge.

Diener, A. C. (2012), Borders: A Very Short Introduction, Oxford: Oxford University Press.

Fernandez Rosa, C. (2015), Brazilian Bodies and Their Choreographies of Identification, London: Palgrave Macmillan.

Fernandez Rosa, C., Bianco, M. and Duque, A. T. (2020), 'Decolonizing performance philosophies', in L. Cull and A. Lagaay (eds), The Routledge Companion to Performance Philosophy, London: Routledge.

Fortuna, V. (2017), 'Between the cultural center and the villa: Dance, neoliberalism, and silent borders in Buenos Aires', in R. Kowal, G. Siegmund and R. Martin (eds), The Oxford Handbook of Dance and Politics, Oxford: Oxford University Press, pp. 371-94.

Franko, M., Lepecki, A., Pape, T., Solomon, N. and Thain, A. (2014), 'Welcome to this situation: Tino Sehgal's impersonal ethics', Dance Research Journal, 46:3, pp. 89-100.

Gallagher, S. (2005), 'Dynamic models of body schematic processes', in H. De Preester and V. Knockaert (eds), Body Image and Body Schema, Amsterdam: John Benjamins Publishers, pp. 233-50.

Gallagher, S. (2017), 'Theory, practice and performance', Journal of Connection Science, 29:1, pp. 106-18.

Geiseking, J. (2016), 'Crossing into territories of the body: Urban territories, borders and lesbianqueer bodies in New York city', Area, 48:3, pp. 262-71.

H2 Dance (2017), Strangers and Others, Deptford: Fest en Fest, Albany Theatre.

Hanna, T. (1990), 'Clinical somatic education: A new discipline in the field of health care', Somatics, Autumn/Winter, p. 6.

Hunter, V. (2015), Moving Sites, London: Routledge.

Hunter, V., Kloetzel, M. and Barbour, K. (2019), 'Dancing urbanisms', Choreographic Practices, 10:1, pp. 3-6.

Kloetzel, M. (2015), 'Site-specific dance in corporate landscape: Space, place, and non-place', in V. Hunter (ed.), Moving Sites, London: Routledge, pp. 239-54.

Kowal, R., Siegmund, G. and Martin, R. (2017), The Oxford Handbook of Dance and Politics, Oxford: Oxford University Press. 
Kurki, T. (2014), 'Borders from the cultural point of view', Culture Unbound, 6:6, pp. 1055-70.

Leigh Foster, S. (2011), Choreographing Empathy, London and New York: Routledge.

Marcalo, R. (2016), Dancing with Strangers: From Calais to England, Manchester: Instand Dissidence.

Hazard Festival, https://dwsfromcalaistoengland.tumblr.com/yoditemelkU. Accessed 5 March 2018.

McKinnon, K. (2016), 'The geopolitics of birth', Area, 48:3, pp. 285-91.

Midgelow, V. (2019), 'Practice-as-research', in S. Dodds (ed.), The Bloomsbury Companion to Dance Studies, London and New York: Bloomsbury Academic, pp. 111-44.

Nelson, R. A. (2013), Practice as Research in the Arts, Basingstoke, Oxford and New York: Palgrave Macmillan and Oxford University Press.

Reynolds, D. (2012), Kinesthetic Empathy in Creative and Cultural Practices, London: Intellect.

Richards, M. E. (2017), 'The orchestrated crowd: Choreography, chorus, conceit in Tino Sehgal's These Associations', Choreographic Practices, 8:2, pp. 181-98.

Rubinstein, S. and Macpherson, H. (2018), Active Maps, London: Migration Museum.

Smith, S., Swanson, N. W. and Gokariksel (2016), 'Territory, bodies and borders', Area, 48:3, pp. 258$61,258$.

Spencer, C. (2017), 'Is This is a Waste Land?', Charlotte Spencer Projects, London: Dance Umbrella, https://charlottespencerprojects.org/projects/is-this-a-waste-land-2015/. Accessed 17 February 2018.

Swale, J. (2015), Drama Games for Rehearsals, London: Nick Hern Books.

Varela, F. J., Thompson, E. and Rosch, E. (1991), The Embodied Mind: Cognitive Science and Human Experience, Cambridge, MA: MIT Press.

White, G. (2013), Audience Participation in Theatre: Audience of the Invitation, Basingstoke: Palgrave Macmillan.

\section{Suggested citation}

Munro, Jane (2020), 'Crossing over: Choreographing audiences over borders - Forms and problematics', Choreographic Practices, 11:2, pp. 259-278, doi: https://doi.org/10.1386/chor_00022_1

\section{Contributor details}

Jane Munro is a dance researcher, choreographer/performance maker. She holds a BA (Hons) from the Laban Centre and a practice as research Ph.D on participatory contemporary dance. She teaches movement to performers, performance-making and practice as research at Central and has recently been an external examiner at the University of Bedford. 
Alongside choreographing, Jane performs both in dance and performance pieces, including improvised dance /music project: Murmurist (2016/2017), with Rebecca Bogue a long term collaborator, and recently created Four Feet and Kitchen with her 10 year old daughter in the Domestic season in October 2020 for Word of Warning.

Jane's current practice looks at participation and dance, auto-biographic practice as well as community dance. In 2019, she worked with Music and Detention to create the Dance in Detention project between an Immigration Removal Unit and Psychiatric Hospital. In 2020, she has also created De-stress Through Movement, an Arts Activity Pack for Detainees for Music in Detention on which she is currently writing.

Contact: Royal Central School of Speech and Drama, Eton Avenue, London, NW3 3HY, UK.

E-mail: j.munro@cssd.ac.uk

Jane Munro has asserted their right under the Copyright, Designs and Patents Act, 1988, to be identified as the author of this work in the format that was submitted to Intellect Ltd.

\section{Notes}

1. The piece was developed between 2016 and 2018 with my collaborator Rebecca Bogue, my article discusses the practical developments made across the four iterations of Rope Piece, performed at the Styxx, Tottenham, London (October 2016), FliaArt, London (December 2016), at the Library Theatre, Covent Garden, London (2017), at the Dialogues on Dance Conference Coventry University (2017) and in a workshop at Royal Central School of Speech and Drama (2017).

2. Embodied cognition examines the arguments to which this responds. Particularly, a consideration of body schema is significant.For a more detailed consideration of EC and body schema, see Gallagher's (2017) review of cognitive arguments which, following Berlucchi and Aglioti (2010), suggests body schema are maps of the brain, an arrangement of sensory-motor faculties that work automatically without focus or awareness.

3. Writing this in 2020 COVID times, there is a sense of loss and sadness at the closeness that was possible then. 